\title{
Pemberdayaan Kelompok Masyarakat Non Produktif Melalui Budidaya Jamur Tiram Di Desa Darek
}

\author{
Septiana Dwi Utami, Hunaepi, Sri Novita Primawati, Ali Imran, Siti Rabiatul Fajri \\ Universitas Pendidikan Mandalika (UNDIKMA) \\ Email: septianadewiutami@ikipmataram.ac.id, hunaepi@ikipmataram.ac.id, \\ srinovitaprimawati@ikipmataram.ac.id, aliimran@ikipmataram.ac.id, \\ sitirabiatulfajri@ikipmataram.ac.id \\ Email Korespodensi: hunaepi@ikipmataram.ac.id
}

\begin{abstract}
ABSTRAK
Kegiatan pengabdian kepada masyarakat ini akan dilaksanakan di Desa Darek Kecamatan Praya Barat Daya Kabupaten Lombok Tengah. Pemilihan tempat pengabdian ini dilakukan berdasarkan potensi yang ada dan kondisi suhu serta kelembaban di lingkungan desa Darek sangat memadai dan mendukung untuk pembudidayaan jamur tiram. Selain itu, penduduk Desa tidak punya pekerjaan tetap sehingga sangat perlu untuk diberdayakan. Tujuan pengabdian untuk memberdayakan kelompok masyarakat yang tidak produktif melalui budidaya jamur tiram. Kegiatan penagbdian melibatkan kelompok masyarakat di desa darek yang tidak produktif berjumlah 40 orang. Metode dan pendekatan yang digunakan dalam kegiatan ini adalah dengan diskusi dan praktek (learning by doing) gabungan kedua metode tersebut diharapkan mampu meningkatkan pemahaman dan keterampilan berkaitan dengan budidaya jamur tiram. Hasil dari kegiatan 1) peningkatan pemahaman dan kreatifitas masyarakat non produktif dalam budidaya jamur tiram, 2) peningkatan keterampilan masyarakat dalam budidaya jamur tiram, 3) menghasilkan bahan pangan berupa jamur tiram yang dapat dikonsumsi oleh masyarakat setempat maupun masyarakat lainnya. Kegiatan pemberdayaan perlu ditingkatkan sehingga masyarakt nonproduktif dapat mandiri secara ekonomi.

Kata Kunci: Masyarakat, Non Produktif, Budidaya Jamur Tiram, Ekonomi
\end{abstract}

\section{PENDAHULUAN}

Desa Darek merupakan salah suatu desa yang terletak di kecamatan Praya Barat Daya Lombok Tengah Nusa Tenggara Barat. Desa ini terdiri dari sebelas dusun dan sebagian besar masyarakatnya berprofesi sebagai kuli bangunan, peternak dan petani. Beragamnya profesi masyarakat desa Darek menyebabkan banyaknya potensi yang dapat dikembangkan di desa ini. Tetapi pengetahuan masyarakat dalam memanfaatkan potensi tersebut masih kurang sehingga masyarakat tidak dapat mengembangkan usaha lain selain profesi yang mereka jalani. Seiring dengan perkembangan di segala bidang, menyebabkan bergesernyan lahan pencarian bagi masyarakat. Kurangnya skil yang dimiliki masyarakat mengakibatkan banyak masyarakat yang kehilangan pekerjaan, dengan demikian akan berdampak pada menurunnya tingkat perekonomian masyarakat.

Salah satu usaha yang dapat dikembangkan di desa Darek adalah budidaya jamur tiram. Berdasarkan hasil observasi keadaan desa, bahwa desa Darek tergolong masih 
Utami, dkk.

asri dan berada di wilayah dekat dengan hutan memiliki suhu linkungan berkisar antara $22-28^{0} \mathrm{C}$ kondisi ini cocok untuk membudidayakan jamur tiram. Dalam pembudidayaan jamur tiram, suhu lingkungan memegang peranan yang sangat penting untuk pertumbuhan jamur (Hunaepi, dkk 2019; Amelia, dkk 2017) menyatakan bahwa suhu ideal untuk pertumbuhan jamur tiram berkisar $\pm 28^{0} \mathrm{C}-30^{\circ} \mathrm{C}$. Mahardian dan Hunaepi (2014) Menyatakan bahwa Pada fase pembentukan miselium, jamur tiram membutuhkan suhu 22-28 $\mathrm{C}$ dan kelembaban 60\%-80\%. Pada fase pembentukan tubuh buah memerlukan suhu 16-22 $\mathrm{C}$ dan kelembaban $80 \%-90 \%$ dengan kadar oksigen 10\%. (Kananga, dkk. 2014; Hunaepi, dkk. 2019) Pertumbuhan jamur tiram sangat tergantung pada faktor fisik seperti suhu, kelembaban, cahaya, tingkat keasaman $\mathrm{pH}$, kadar air, media tanam, dan aerasi.

Jamur tiram atau dalam bahasa latin disebut Pleurotus sp. Merupakan salah satu jamur konsumsi yang bernilai tingi. Beberapa jenis jamur tiram yang biasa dibudidayakan oleh masyarakat Indonesia yaitu jamur tiram putih (P.ostreatus), jamur tiram merah muda P.flabellatus), jamur tiram abu-abu ( $P$. sajor caju), dan jamur tiram abalone (P.cystidiosus). Pada dasarnya semua jenis jamur ini memiliki karateristik yang hampir sama terutama dari segi morfologi, tetapi secara kasar, warna tubuh buah dapat dibedakan antara jenis yang satu dengan dengan yang lain terutama dalam keadaan segar (Susilo, Rikardo, \& Suyamno, 2017).

Pembudidayaan jamur tiram tidak membutuhkan lahan yang terlalu luas serta perawatannya mudah dan tidak terlalu mahal. Hal yang lebih mendukung adalah bahanbahan yang digunakan untuk pengembangan budidaya jamur ini sangat banyak tersedia di desa Darek, yaitu limbah serutan kayu atau serbuk kayu yang berasal dari rumah produksi kayu potong (tempat sumil) dan tukang bangunan serta dedak halus (bekatul) yang berasal dari penggilingan padi. Hunaepi, dkk (2019) Serbuk gergaji kayu merupakan bahan utama yang dipakai sebagai media tumbuh dalam memproduksi jamur dengan baglog. Kayu merupakan media utama tumbuh jamur tiram di alam sehingga serbuk gergaji kayu sangat cocok untuk media budidaya. Dedak halus (Bekatul) dalam media jamur berfungsi sebagai sumber karbohidrat dan mineral jamur.

Kondisi lingkungan dan keberadaan potensi lokal yang ada di desa darek sangat memungkinkan untuk membudidayakan jamur tiram sebagai salah satu alternatif untuk mengembangkan produktifitas masyarakat desa Darek yang nonproduktif. Tujuan dari kegiatan ini adalah untuk meningkatkan pemahaman dan keterampilan masyarakatan non produktif dalam pemanfatan potensi lokal berupa serbuk gergaji untuk dijadikan media budidaya jamur tiram.

\section{METODE}

Metode dan pendekatan yang digunakan dalam kegiatan ini adalah dengan diskusi dan praktek (learning by doing) gabungan kedua metode tersebut diharapkan mampu meningkatkan pemahaman dan keterampilan berkaitan dengan budidaya jamur tiram. Adapun tahapan dalam kegiatan sebagai berikut

A. Desk study dan Survey

1. Desk study menelusuri dan mengevaluasi data sekunder dan study yang terkait

2. Melaksanakan survey data lapangan untuk memperoleh data lokasi dan kondisi sosial masyarakat secara mendetail 
3. Menyiapkan buku pedoman tentang budidaya jamur tiram dengan pemanfaatan potensi lokal

B. Penyuluhan

1. Penyuluhan cara membudidayan jamur tiram kepada masyarakat desa darek yang diwakili masing-masing oleh 5 orang dari 11 Dusun. Kegiatan ini bertujuan untuk memberikan pemahaman tentang proses budidaya jamur tiram.

2. Pelatihan budidaya jamur tiram, pelatihan ini dilakukan setelah proses penyuluhan dengan tujuan untuk mempraktikkan materi yang yang telah diberikan pada saat penyuluhan.

C. Pelatihan

Adapun dalam pembudidayaan jamur tiram, ada beberapa tahapan yang harus diperhatikan oleh pembudidaya jamur tiram, yakni berupa persiapan media (substrat), pencampuran media, pengantongan, sterilisasi, inokulasi bibit, inkubasi, pemeliharaan tubuh bibit, dan panen.

D. Pendampingan

Pendampingan dilakukan oleh tim pengabdian untuk memastikan keberlanjutan dari kegiatan budidaya jamur tiram oleh masyarakat mitra. Selain itu pendampingan dilakukan sampai masa panen dan proses pengemasan dan penjualan.

\section{HASIL DAN PEMBAHASAN}

A. Studi lapangan

Survey lapangan dilaksanakan untuk memperoleh data lokasi dan kondisi sosial masyarakat secara mendetail. Survey ini dilaksanakan di Desa Darek Kecamatan Praya Barat Daya pada tanggal 17 September 2016 untuk mendapatkan informasi secara mendalam dan mendetil tentang kondisi masyarakat sekitar. Kegiatan ini dilaksanakan dengan melaksanakan pengamatan di Desa Darek Kecamatan Praya Barat Daya dan melaksanakan diskusi dengan beberapa masyarakat yang ditemui. Dari hasil pengamatan dan diskusi, diperoleh informasi bahwa di desa darek terdapat usaha pemotongan kayu (sumil) dan banyak masyarakat yang bekerja sebagai tukang bangunan khususnya pembuat kusen sehingga di desa darek ini banyak terdapat serbuk kayu yang tidak dimanfaatkan oleh warga. Di desa darek juga terdapat dua buah heler (penggilingan padi) sehingga sangat mudah sekali untuk mendapatkan dedak yang merupakan bahan tambahan pembuatan baglog jamur tiram.

Dari proses surve didapatkan kesepakatan dengan perangkat desa dan mitra tentag jadwal pelaksanaan dan tempat pelaksanaan dan metode pelaksanaan. selain itu beberapa kebutuhan dan pasilitas selama kegiatan tim pengabdian bersama prangkat desa serta masyarakat mitra secara bersama-sama menyediakan.

\section{B. Hasil Pelatihan Dan Pendampingan}

Pelaksanaan pelatihan dan pendampingan dilaksanakan secara berkala. Setiap pelatihan juga mendatangkan narasumber yang ahli di bidang kajian sesui materi pelatihan. Ada beberapa pelatihan dan pendampingan yang dilaksanakan.

1. Penyuluhan tentang Budidaya Jamur Tiram

Kegiatan ini dilaksanakan pada hari Sabtu tanggal 8 Oktober 2016 dengan tujuan untuk membuka wawasan masyarakat desa Darek tentang budidaya Jamur 
Utami, dkk.

Tiram. Materi disampaikan oleh narasumber yang sudah berpengalaman dalam pembudidayaan jamur tiram. Materi yang disampaikan meliputi peluang usaha dan teknik budidaya jamur tiram.

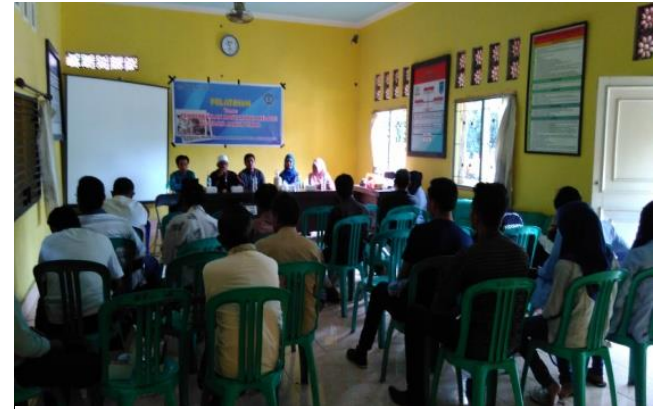

Gb 1. Sosialisai Kegiatan Pengabdian yang dibuka oleh Kepala Desa Darek

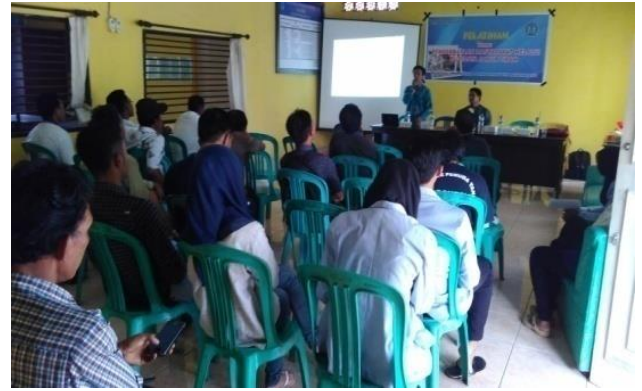

Gb 2. Penyampaian materi pelatihan

Semangat dan antusias peserta dalam mengikuti kegiatan penyuluhan ditunjukkan dengan partisipasi melalui bertanya, selain itu terdapat peningkatan pemahaman tentang peluang bisnis jamur dan proses budidaya jamur dengan pemanfatan limbah serbuk gergaji.

\section{Pelatihan pembuatan media jamur tiram (baglog)}

Setelah selesai penyampaian materi tentang pelatihan budidaya jamur tiram, dilanjutkan dengan pelatihan pembuatan baglog. Pelatihan ini diikuti oleh seluruh peserta. Pelatihan pembuatan baglog dimulai dengan tahapan sebagai berikut;

a. Persiapan Media (Substrat), adapun media tanam untuk jamur tiram adalah sebai berikut: Serbuk gergajian kayu $=100 \mathrm{~kg}$, Dedak $=10 \mathrm{~kg}$, Kapur $=0,5 \mathrm{~kg}$, Tepung jagung $=0,5 \mathrm{~kg}$, Gula merah $=0,25 \mathrm{~kg}$, TSP $(\operatorname{tambahan})=0,25 \mathrm{~kg}$.

b. Pencampuran Media Tanam: Bahan media tanam yang telah disiapkan diaduk sedemikian rupa samapi homogen agar pertumbuhan miselium dapat merata ke seluruh media tanam. Kemudian pengadukan dapat dilakukan dengan cara mekanis maupun secara manual. Apabila dilakukan secara manual upayakan pengadukan lebih lama sehingga diperoleh pencampuran yang merata terutama untuk bahan bahan yang konsentrasinya rendah. Media yang telah tercampur dengan baik biasanya menggumpal pada saat dikepal. Bila proses pencampuran dilakukan pengomposan (fermentasi) selama 3-5 hari. Proses pengomposan dapat membantu untuk mengurangi kontaminasi oleh mikroba liar dan juga membantu penguraian beberapa senyawa kompleks untuk menjadi lebih sederhana sehingga lebih mudah diserap oleh jamur tiram. pengadukan dilakukan setiap hari dagan tujuan proses pengomposan merata.

c. Pengantongan atau pembuatan baglog dilakukan dengan memasukkan media yang telah dikompos ke dalam plastik tahan panas (polypropylene). Dan diupayakan pengisian tidak terlalu longgar dan juga padat. Untuk memadatkan media dapat dilakukan dengan bantuan botol yang diisi dengan pasir. Setelah diisi media pada bagian atas lalu diberi ring bambu, leher botol, gulungan kertas, dan bisa juga pipa dan di tutup dengan kapas sebagai sebagai sumbu dan sekaligus tempat memasukkan bibit atau tempat keluarnya jamur. setelah itu diikat dengan karet

d. Sterilisasi baglog melalui proses pasteurisasi dengan cara dikukus. Pasteurisasi yaitu proses pemanasan dengan suhu tidak lebih dari $100^{\circ} \mathrm{C}$ dengan waktu tidak 
kurang dari 5 jam. Pada umumnya para produsen melakukan pemanasan selama 812 jam. Pemanasan ini tergantung pada bahan dasar yang digunakan dan banyaknya log yang dipasteurisasi. Setelah selesai baglog didinginkan selama setengah sampai satu hari baru bisa digunakan.

Pada tahap pertama di hasilkan 50 buah baglog dengan berat setiap baglog 2 kg. kegiatan pelatihan tahap pertama untuk memastikan bahwa peserta atau mitra telah mampu mengaplikasikan pemahaman materi yang telah dijelaskan. Adapun proses kegiatan pelatihan seperti yang terlihat pada gambar berikut;

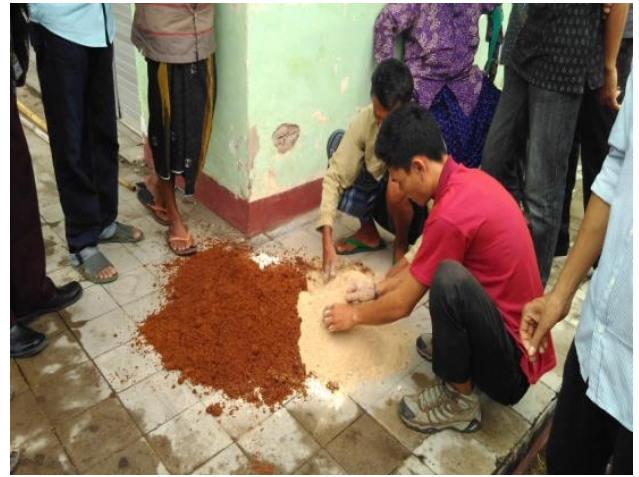

Gb. 4. Proses pencampuran bahan

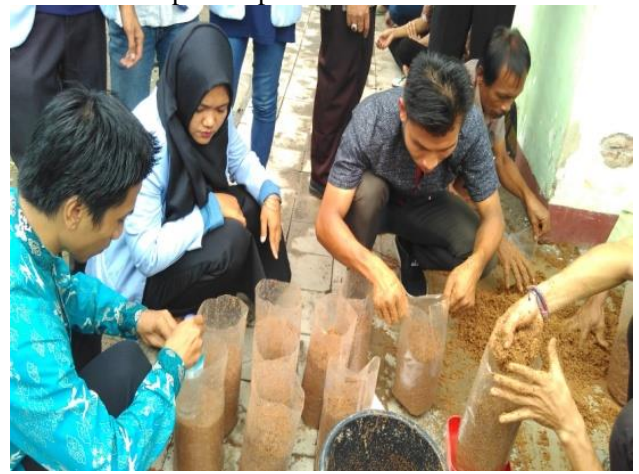

Gb. 6. Proses pengisian bahan ke dalam plastik baglog
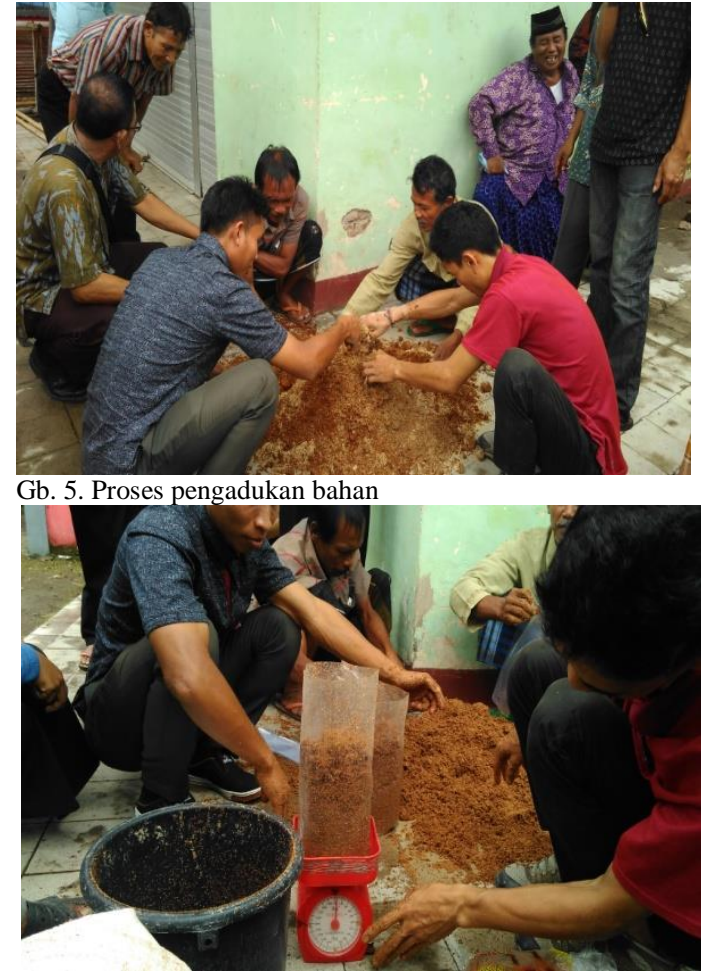

Gb. 7. Proses penimbangan baglog

\section{Pelatihan inokulasi}

Sebelum dilakukan inokulasi, terlebih dahulu dilakukan sterilisasi baglog melalui proses pasteurisasi dengan cara dikukus.selama 8-12 jam. Proses inokulasi dilakukan secara steril. Ruangan diusahakan sebersih mungkin dan steril. Bila memungkinkan peralatan maupun ruangan disemprot alkohol terlebih dahulu. Selama proses ini disarankan menggunakan masker atau minimal tidak berbicara berlebihan untuk menghindari kontaminasi yang berasal dari uap mulut. Inokulasi dilakukan dengan memasukkan bibit (F2) sebanyak 2-5 sendok makan ke dalam lubang yang telah diberi cincin pipa atau bisa juga dengan menebarkannya di atas permukaan media hingga merata kemudian menutup kembali lubang ring bambu dengan kapas.

Setelah dilakukan proses inokulasi maka baglog siap untuk diinkubasi yaitu masa pertumbuhan miselium hingga memenuhi media secara merata. Suhu yang dibutuhkan pada proses ini yaitu antara $22^{\circ} \mathrm{C}-28^{\circ} \mathrm{C}$. diupayakan suhu ruangan inkubasi dijaga agar tetap stabil sehingga dapat menghasilkan pertumbuhan jamur yang optimum. inkubasi dilakukan selama kurang lebih 40 hari. 
Utami, dkk.

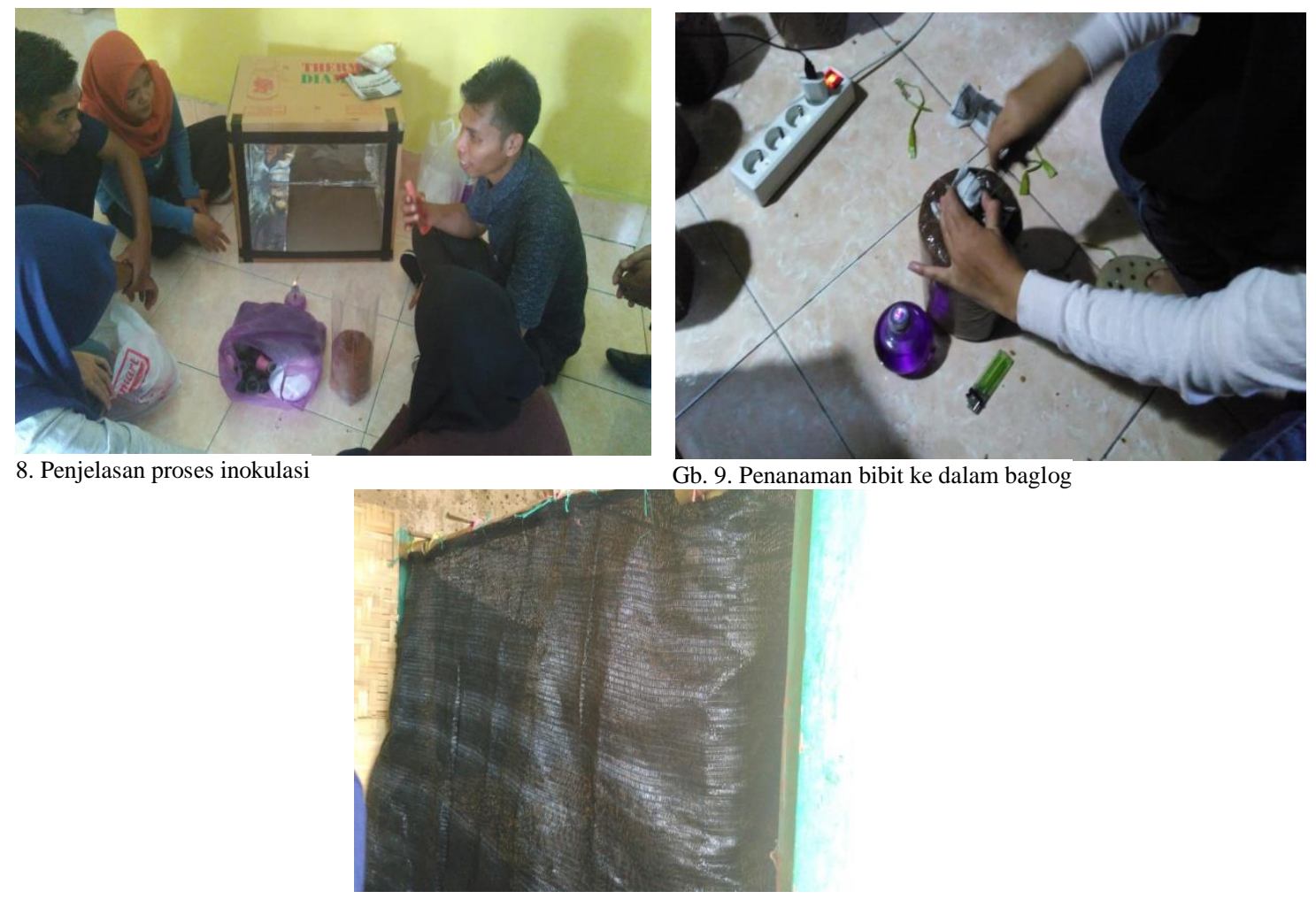

Gb 10. Kumbung yang digunakan untuk inkubasi

4. Pemeliharaan tubuh bibit. Pada masa pemeliharaan ini penutup baglog dibuka hingga seperempat bagian. Tahapan ini memerlukan suhu yang lebih rendah dibandingkan pada saat pertumbuhan miselium (tahap inkubasi) dan juga kelembapan yang optimum/berlimpah. Suhu yang diperlukan sekitar $20{ }^{\circ} \mathrm{C}-26^{\circ} \mathrm{C}$ dengan kelembapan $80 \%-90 \%$. Pengaturan kelembapan dapat dilakukan dengan penyiraman sebanyak 2-3 kali setiap hari terutama ketika kelembapan di luar rendah biasanya pada saat siang hari. Selain kelembapan, kadar oksigen juga perlu diatur dengan membuka ventilasi ketika kelembapan di luar tinggi. Kelembapan perlu dikurangi hingga $70 \%-80 \%$ apabila tubuh bibit telah mencapai ukuran dewasa. Hal ini dilakukan untuk menghindari tekstur tubuh bibit tidak lembek yang bisa menyebabkan tidak tahan lama atau cepat busuk.

5. Panen dilakukan setelah 7-10 hari penutup dibuka, tubuh bibit biasanya sudah mulai tumbuh. Selang 3-4 hari setelah tunas tubuh bibit tumbuh, menunjukkan jamur telah siap dipanen. Pemanenan harus dilakukan dengan hati-hati dengan cara mencabut seluruh rumpun tubuh bibit jamur yang ada beserta akarnya. Karena akar yang tertinggal bisa menyebabkan pertumbuhan tubuh bibit selanjutnya terganggu karena terjadi pembusukan media. Panen sebaiknya dilakukan pada pagi atau sore hari pada saat jamur masih dalam kondisi segar. Panen kedua biasanya berlangsung dalam rentang waktu 1-2 minggu setelah panen pertama. Usia produktif berlangsung 3-4 bulan dengan produksi satu baglog sekitar 0,6 kg. Setelah 
dilakukan pemanenan, log dipelihara seperti awal penanaman yaitu dengan melakukan penyiraman, pengaturan suhu, kelembapan serta aerasi.

\section{SIMPULAN DAN REKOMENDASI}

Berdasarakan hasil pelaksnaaan kegiatan, maka dapat disimpulkan bahwa mitra yang dibina telah memahami prosedur atau cara pembuatan media budidaya jamur tiram dengan menanfatakan potensi lokal berupa serbuk gergaji dan dedak halus (bekatul) dan telah memiliki pengetahuan dan keterampilan dalam membudidayakan jamur tiram sebagai salah satu usaha untuk meningkatkan produktifitas perekonomian. Kegiatan pemberdayaan dalam budidaya jamur tiram perlu ditingkatkan dan perlu di fasilitasi oleh kepala desa melalui bumdes sehingga masyarakat nonproduktif dapat mandiri secara ekonomi.

\section{DAFTAR PUSTAKA}

Amelia. F., Frdinand. J., Maria. K., Waluyan. G.M., dan Sari. I. 2017. Pengaruh Suhu dan Intensitas Cahaya Terhadapa Pertumbuhan Jamur Tiram di Tangerang. Jurnal Biogenesis.5(1)1-6. DOI: https://doi.org/10.24252/bio.v5i1.3426

Hunaepi, Asy'ari, M, Samsuri, T., Mirawati, B., Firdaus, L., Fitriani, H., Muhali, Prayogi, S. (2019). Budidaya Jamur Tiram di Pondok Pesantren Hidayaturrahman NW Manggala. Sasambo: Jurnal Abdimas (Journal of Community Service), 1(1), 45-52. doi: 10.36312/sasambo.v1i1.119

Mahardian. G. dan Hunaepi. 2014. Pengaruh Penggunaan evaporative pad Terhadap Iklim Mikro pada Rumah Jamur Tiram (Pleurotus ostreatus) Berdinding Jerami Di Musim Kemarau. Jurnal Bioscientist. 2(1) 240-249.

http://ojs.ikipmataram.ac.id/index.php/bioscientist/article/view/1311

Kenanga. P., Pambudi. A., dan Puspitasari. L.R. 2014. Perbandingan Pertumbuhan Jamur Tiram Putih di Kumbug Ciseeng dan Universitas Al-Azhar Indonesia. $\begin{array}{llll}\text { Jurnal Al. } & \text { Kauniah. }\end{array}$ https://doi.org/10.15408/kauniyah.v7i2.2721

Hunaepi, Samsuri T. , Asy'ari M., Mirawati B., dan Firdaus, L. (2019) Budidaya Jamur Tiram Di Pondok Pesantren. Mataram. Penerbit Litpam. https://scholar.google.co.id/citations?hl=id\&user=mrMMX20AAAAJ\#d=gs_md citad\&u=\%2Fcitations\%3Fview_op\%3Dview_citation\%26hl\%3Did\%26user\%3D mrMMX20AAAAJ\%26citation_for_view\%3DmrMMX20AAAAJ\%3AwbdjCoPYUoC\%26tzom\%3D720

Susilo H., Rikardo R, \& Suyamno, 2017. Pemanfaatan Limbah Serbuk Gergaji Sebagai Media Budidaya Jamur Tiram (Pleourotus Ostreatusl). Jurnal Pengabdian Pada Masyarakat. 2(1)51-56. https://media.neliti.com/media/publications/123878-ID$\underline{\text { none.pdf }}$ 